ISSN 1112-9867

http://www.jfas.info

\title{
ANTISTRESS AND ANTIMICROBIAL STUDIES OF BIPHENYL CHALCONE DERIVATIVES
}

C. G. Darshan Raj ${ }^{1 *}$, B. K. Sarojini ${ }^{2}$, E. S. Sindhu Priya ${ }^{3}$, M. T. Hassan Khan ${ }^{4}$, C.Srinivas ${ }^{5}$, P.S Manjula ${ }^{1}$

${ }^{1}$ Department of Chemistry, P.A. College of Engineering, Nadupadavu, Mangalore 574153, Karnataka, India

${ }^{2}$ Department of Industrial Chemistry, Mangalore University, Mangalagangothri, Mangalore 574199, Karnataka, India

${ }^{3}$ Department of Pharmacology \& Yenepoya Research Centre, Yenepoya University, Deralakatte, Mangalore-574153

${ }^{4}$ Holmoboevegen 3B, 9010 Troms $\varnothing$, Norway

${ }^{5}$ Department of Radiationtheraphy and oncology, Kasturba Medical College Hospital, Attavar, Mangalore-575001, Karnataka, India

Received: 02 April 2016 / Accepted: 17 August 2016 / Published online: 01 Septembre 2016

\begin{abstract}
This work reports the synthesis, characterization of new (2E)-1-(biphenyl-4-yl)-3-aryl)-prop-2-en-1-one derivatives (C1-C10). The chalcone derivatives were evaluated for in vitro antibacterial, antifungal, antioxidant activities. The compounds exhibited moderate to good antimicrobial activity at MIC $10-40 \mu \mathrm{g} / \mathrm{mL}$. The compounds were docked at the active site of the methionyl-tRNA synthetase (metRS) (PDB ID: $1 \mathrm{~A} 8 \mathrm{H})$ to predict their putative interactions.
\end{abstract}

Author Correspondence, e-mail: darshanraj22@gmail.com

doi: http://dx.doi.org/10.4314/jfas.v8i3.7 
The compounds further screened for antioxidant property, amid C5, C7 and C8 exhibited good DPPH radical scavenging activity. Compound C5 was selected for antistress studies against gamma radiation induced oxidative stress markers in $E$.coli $\mathrm{K} 12$. The $\mathbf{C 5}$ pretreatment and irradiated bacteria sample showed modulatory action of stress enzymes SOD and CAT to near basal level and significant demulating effect on the level of TBARS.

Keywords: Biphenyl chalcone derivatives, radioprotection, antioxidant activity, antimicrobial activity, molecular docking.

\section{INTRODUCTION}

oxidative stress triggered by even quite low doses of radiation can produce an alteration of the cellular redox balance, which lasts for substantial time after exposure and may contribute to bystander effects, genomic instability, modified gene expression, elevated mutagenesis rates, changes in cell survival, proliferation, and differentiation. Ionizing radiation can damage all important cellular components, including DNA and proteins, both through direct ionization and through induction of oxidative stress. Under normal healthy conditions, a balance is maintained between oxidative stress and antioxidant requirements. [1]

However, under pathological conditions, during stress, smoking, or radiation injury, the balance is lost and additional supplementation of antioxidants is necessary. The search for new, effective and appropriate antioxidants aimed at minimizing the oxidative stress and providing defence against free radical induced stress in diverse clinical and pathological conditions has gained a lot of importance [2].

The increasing need for new antibiotics to overcome rapidly developing resistance mechanisms observed in clinical isolates of Gram-positive and Gram-negative bacteria has placed critical emphasis on the search for new antibacterial enzyme targets and the structural and mechanistic investigation of such targets. Many tRNA synthetases can be considered good targets for antibacterial discovery because they are broadly conserved, essential for growth, and distinct enough from their human orthologs to anticipate the discovery of selective inhibitors $[3,4]$.

Chalcones (trans-1,3-diphenyl-2-propen-1-ones) are the biogenetic precursors of all known 
flavonoids and are abundant in edible plants. [5]. Scientific investigations on the bioavailability of chalcones from food sources are limited but variety of synthetic chalcones has been reported to possess a wide range of pharmaceutically important biological activities like antimicrobial antimalarial, antileishmanial, anticancer and antioxidant $[6,7]$.

In the present study the biphenyl substituted chalcone derivatives were synthesized, characterized and evaluated for in vitro anti oxidant through chemical antioxidant assays like DPPH scavenging assay. Selected compounds were further screened for antioxidant property by radiation induced oxidative stress in E. coli $\mathrm{K} 12$ bacteria strain. The compounds were also screened for antimicrobial efficacy against selected strains of both gram positive and negative bacteria. An in silico docking of the newly synthesized compounds to methionyl-tRNA synthetase enzyme was attempted to support antimicrobial efficacy of the compounds.

\section{RESULTS AND DISCUSSION}

\subsection{Chemistry}

The Claisen-Schmidt condensation is an important C-C bond formation for the synthesis of 1,3-diaryl-2-propen-1-ones (chalcones). It is generally carried out using strong bases such as $\mathrm{NaOH}$ or $\mathrm{KOH}$ in polar solvents $(\mathrm{MeOH} / \mathrm{EtOH}$ or DMF). The yields of the synthesized compounds were found to be significant. The structure of the synthesized compounds was confirmed by IR, ${ }^{1} \mathrm{H}$ NMR, LCMS and elemental analysis. Elemental analysis showed that the percentage of the hydrogen and carbon was found to be experimentally equivalent to the calculated values for all compounds. LCMS of the synthesized chalcones showed peak corresponding to the molecular mass. In ${ }^{1} \mathrm{H} \mathrm{NMR}(400 \mathrm{MHz})$ spectrum of $\mathbf{C 5}$ a singlet appeared at $\delta 3.83$ was due to $\mathrm{OCH}_{3}$ substituent of the phenyl ring. The signal due to two olefinic protons appeared at $\delta 7.02-7.05$ as a doublet. The multiplet appeared in the region $\delta$ $7.4-8.2$ could be attributed to the aromatic protons present in the molecule. This spectral data confirmed the formation of the compound 1- biphenyl -3(4-methoxyphenyl-prop-2-en-1-one (C5). The spectral characterizations of all the compounds are given in the Experimental section. The synthetic pathway is presented in Scheme $\mathbf{1}$ and physicochemical data for the synthesized compounds are given Table $\mathbf{1}$. 
Table 1. Analytical data of chalcone derivatives C1-C10

\begin{tabular}{|c|c|c|c|c|}
\hline \multirow[t]{2}{*}{ Compound } & \multirow[t]{2}{*}{$\mathrm{MP}\left({ }^{\circ} \mathrm{C}\right)$} & \multirow[t]{2}{*}{$\%$ Yield } & \multicolumn{2}{|c|}{ Elemental analysis Found } \\
\hline & & & $\mathrm{C}$ & $\mathrm{H}$ \\
\hline C1 & $220-02$ & 80 & $88.70[86.45]$ & $5.67[5.24]$ \\
\hline $\mathrm{C2}$ & $170-83$ & 85 & $79.12[82.44]$ & $4.74[4.81]$ \\
\hline C3 & $176-76$ & 78 & $69.44[71.12]$ & $4.16[4.23]$ \\
\hline $\mathrm{C} 4$ & 223-28 & 75 & $83.42[52.90]$ & $5.00[5.09]$ \\
\hline C5 & $180-88$ & 85 & $84.05[85.12]$ & $5.77[5.85]$ \\
\hline C6 & $211-18$ & 89 & $76.99[77.08]$ & $5.92[6.03]$ \\
\hline C7 & $221-27$ & 87 & 80.21 [81.07] & $5.85[6.01]$ \\
\hline C8 & 197-03 & 79 & 80.21 [81.12] & $5.85[6.03]$ \\
\hline C9 & $206-16$ & 84 & $76.58[76.72]$ & $4.74[4.89]$ \\
\hline $\mathrm{C10}$ & $168-71$ & 80 & $67.19[68.11]$ & $4.36[4.41]$. \\
\hline
\end{tabular}

\subsection{Biological evaluation}

\subsubsection{Antioxidant activity by DPPH scavenging assay}

DPPH is a stable radical that has a high absorption at $517 \mathrm{~nm}$. When a odd electron of DPPH is paired up with electron taken from phenolic compounds, the absorption at $517 \mathrm{~nm}$ decreases. The degree of decolorization is a measure of the reducing capacity of compounds and whereby it enables to evaluate their antioxidant activity. The compounds with two or more electron donating groups have lower anodic peak potentials and higher antioxidant abilities than mono-substituted phenols [8]. The ascorbic acid was taken as standard and it exhibited 79.43 $\pm 0.23 \%$ DPPH scavenging. Among the tested compounds C5, C7 and C8 showed $79.95 \pm 0.44,73.46 \pm 0.65$ and $71.66 \pm 0.59 \%$ DPPH scavenging at $15 \mu \mathrm{g} / \mathrm{mL}$. The enhanced radical scavenging capacity of these compounds might be due to the presence of methoxy substitution in the phenyl ring [9]. The DPPH scavenging ability of chalcone derivatives is given in the Fig.1. 


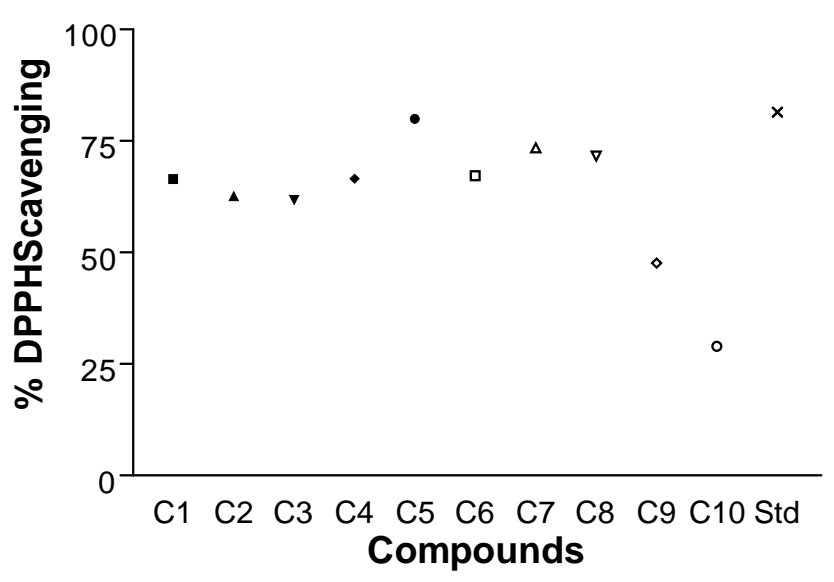

Fig.1. DPPH scavenging ability of the compounds C1-C10

\subsubsection{Modulatory effect of compounds against oxidative stress induced by gamma radiation in E.coli K12}

Radiation dosimetry (absorbed dose to a specific point in Gray or centi-Gray: Gy) was carried out using International Atomic Energy Agency (IAEA) Technical Report Series-398 protocol under the cobalt. Measurements were taken with a calibrated ionization chamber kept inside the water phantom (under full scatter conditions) using the above protocol. The dosimetry of tele cobalt unit is audited periodically under supervision of IAEA / WHO. The audit results are within $\pm 0.2 \%$. The compounds (2E)-1-(biphenyl-4-yl)-3-(4-methoxyphenyl) prop-2-en-1-oneC5, (2E)-1-(biphenyl-4-yl)-3-(2,5-dimethoxyphenyl) prop-2-en-1-oneC7 and (2E)-1-(biphenyl-4-yl)-3-(3,4-dimethoxyphenyl)prop-2-en-1-one C8 were selected to evaluate radioprotective property was based on DPPH scavenging efficacy. The lethal concentration of the compounds for the study was determined by evaluation of minimum inhibitory concentration (MIC). Determination of radioprotective property against radiation induced oxidative stress in E. coli was carried out below MIC of the compounds data is illustrated in table 2. 
Table 2. Antimicrobial activity of new chalcones C1-C10 (Zone of Inhibition in mm)

\begin{tabular}{|c|c|c|c|c|c|c|}
\hline Compounds & $\begin{array}{c}\text { Staphylococcus } \\
\text { aureus }\end{array}$ & $\begin{array}{l}\text { Bacillus } \\
\text { subtilis }\end{array}$ & $\begin{array}{c}\text { Salmonella } \\
\text { typhi }\end{array}$ & $\begin{array}{c}\text { Escherichia } \\
\text { coli }\end{array}$ & $\begin{array}{c}\text { Aspergillus } \\
\text { niger }\end{array}$ & $\begin{array}{l}\text { Candida } \\
\text { albicans }\end{array}$ \\
\hline C1 & 21 & 21 & 20 & 24 & 23 & 20 \\
\hline $\mathrm{C2}$ & 22 & 22 & 22 & 22 & 23 & 21 \\
\hline C3 & 26 & 27 & 26 & 26 & 24 & 21 \\
\hline C4 & 24 & 25 & 23 & 24 & 21 & 23 \\
\hline C5 & 21 & 19 & 23 & 18 & 21 & 17 \\
\hline C6 & 19 & 21 & 20 & 21 & 18 & 17 \\
\hline C7 & 17 & 19 & 17 & 18 & 22 & 11 \\
\hline C8 & 21 & 21 & 23 & 21 & 22 & 22 \\
\hline C9 & 24 & 26 & 24 & 22 & 24 & 24 \\
\hline C10 & 25 & 27 & 26 & 25 & 24 & 19 \\
\hline Standard & 24 & 23 & 23 & 25 & 25 & 24 \\
\hline DMSO(Control) & 0 & 0 & 0 & 0 & 0 & 0 \\
\hline
\end{tabular}

Note: - Standard drug used $\quad$ : Bacteria (Ciprofloxcin), Fungal (Fluconazole) (1 mg /mL Stock concentration).

Compounds used $\quad:(1 \mathrm{mg} / \mathrm{L}$ - based on MIC concentration).

Control : DMSO (dimethyl sulphoxide)

\subsubsection{Enzymatic activity measurements}

Most environmental bacteria experience oxidative stress from a variety of sources. The reactive oxygen species (ROS) can be produced in cells not only during microbial aerobic growth as by-products of normal cellular metabolism but also under stress situations. To explore the ameliorative effect of $\mathbf{C 5}, \mathbf{C 7}$ and $\mathbf{C 8}$ on defensive enzymes in bacteria $E$. coli $\mathrm{K} 12$ was exposed to gamma radiation at 0.2 and 0.4 Gy dose as shown in the Fig.2a and $2 \mathrm{~b}$. 

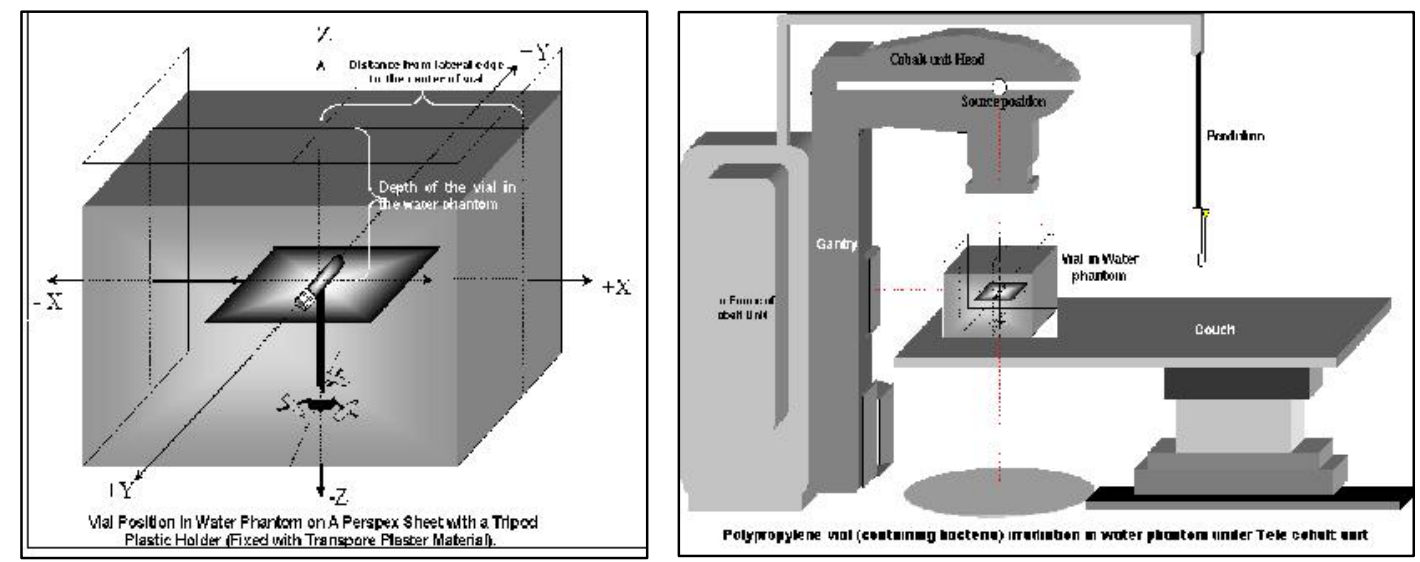

Fig.2. Irradiation of Bacteria samples

a. Irradiation of bacteria sample in water plank set up; b. Cobalt Radiation Unit

The level of SOD and CAT was elevated in the irradiated bacteria homogenate in dose dependent manner. The elevation could be attributed to the induced oxidative stress by gamma radiation. But in the case of compounds $\mathbf{C 5}, \mathbf{C 7}$ and $\mathbf{C 8}$ treated and irradiated bacteria homogenates the level SOD and CAT found to be near basal level. These results indicate the capacity of the compounds in reducing oxidative stress induced by ionizing radiation. The antioxidant property of the molecules might be due to the presence of $\mathrm{OCH}_{3}$ substituent on the phenyl ring. The data is given in the Fig. 3 and 4. 


\section{SOD}

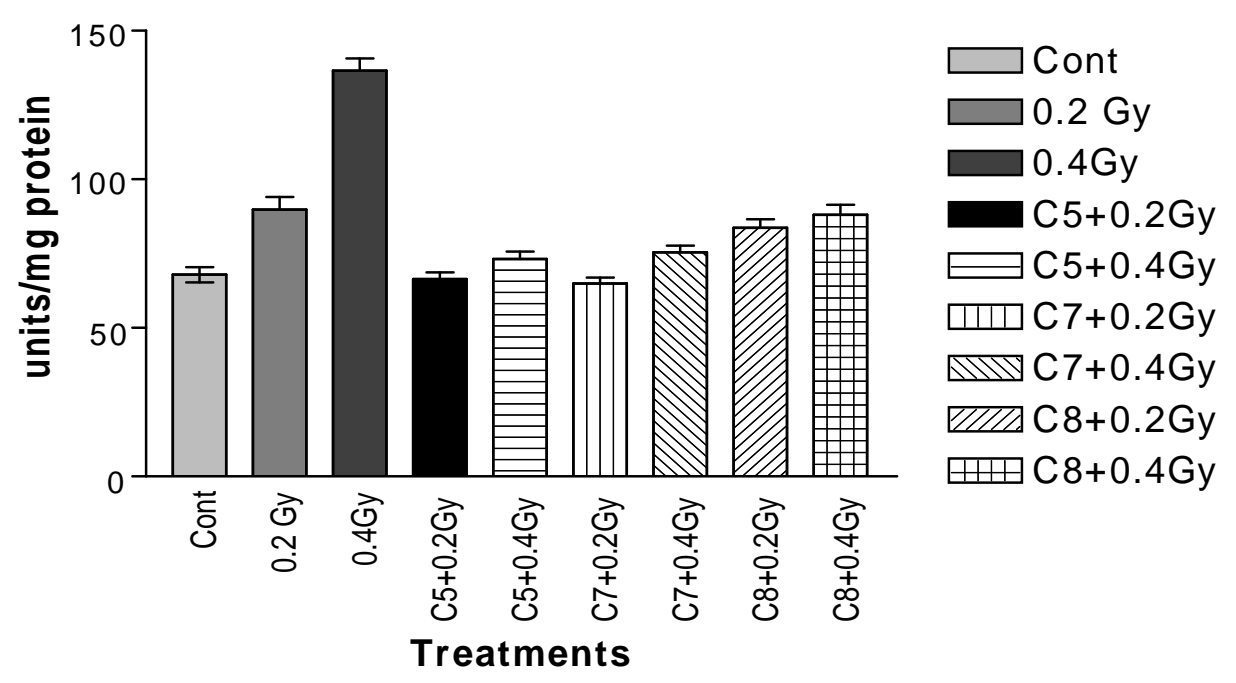

Fig.3. Modulatory effect of C5, C7 and C8 on SOD by radiation induced oxidative stress in E. Coli $\mathrm{K} 12$ bacteria

\section{CAT}
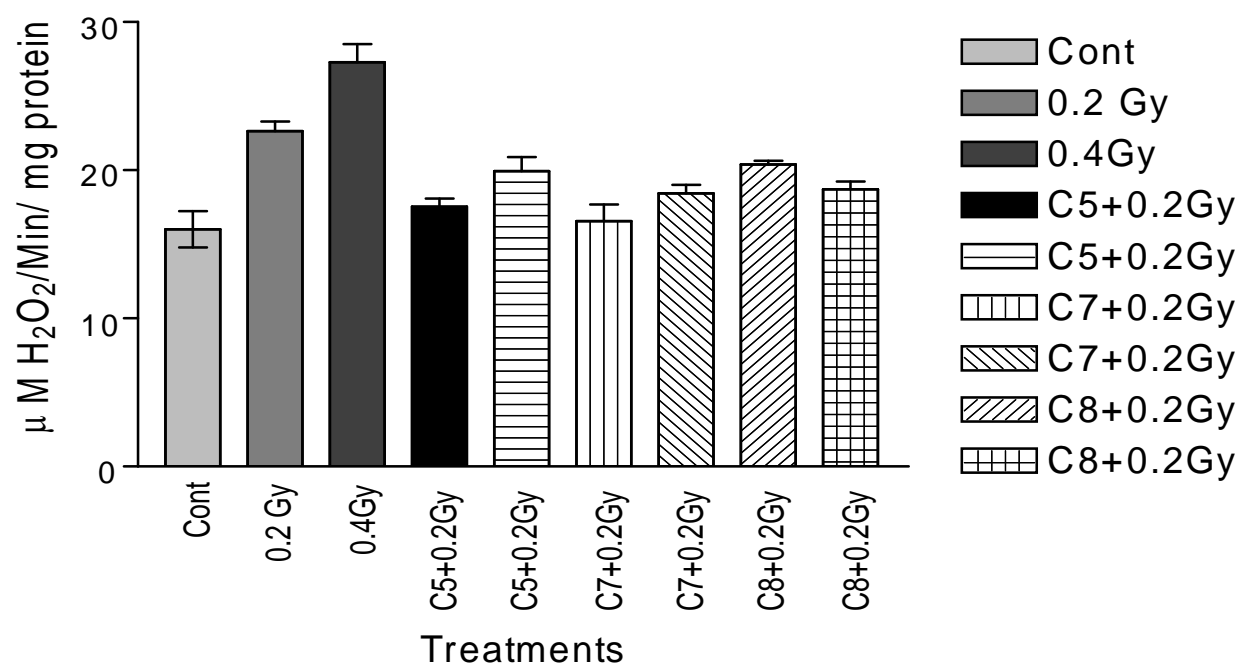

Fig.4. Modulatory effect of C5, C7 and C8 on CAT by radiation induced oxidative stress in E.Coli $\mathrm{K} 12$ bacteria

\subsubsection{TBARS level estimation}

In biological membranes, lipid peroxidation is frequently a consequence of free radical attack. 
The peroxidation of unsaturated fatty acids of cells produces many reactive species, such as free radicals, hydroperoxides, and carbonyl compounds, which may cause damage to proteins and DNA. Lipid peroxidation is a continual process in living aerobic cells; it is maintained at a low level; and it can be prevented from entering into the autocatalytic phase by protective enzymes and antioxidants [10]. Thiobarbituric acid-reactive substances (TBARS) were determined as an independent measurement of lipid peroxidation. The samples were evaluated for malondialdehyde (MDA) production using a lipid peroxidation assay. The level of TBARS was elevated in case of irradiated bacteria sample indicated the presence of oxidative stress. The level of TBARS was found to be decreased significantly in case of C5 treated and irradiated bacteria samples. Where as in case of $\mathbf{C 7}$ and $\mathbf{C 8}$ treated and irradiated samples showed significant decrease in the level of TBARS compared to irradiated bacteria samples. This result supports the antioxidant properties of the compounds. The data is given in the Fig 5.

T B A R S

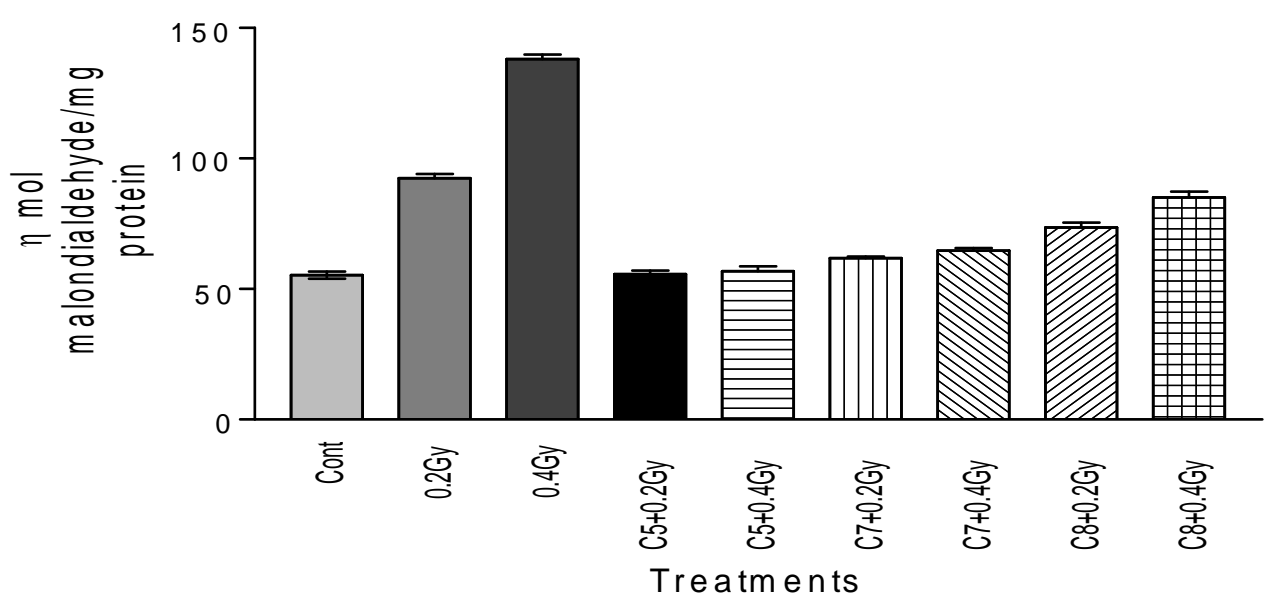

Fig.5. Modulatory effect of C5, C7 and $\mathbf{C 8}$ on TBARS by radiation induced oxidative stress in E. Coli $\mathrm{K} 12$ bacteria

\subsection{Antibacterial studies}

The newly synthesized compounds were also screened for their antibacterial activity against Escherichia coli K-12, Staphyllococcus aureus, Salmonella typhi, and Bacillus subtilis 
bacterial strains by disc diffusion method [11]. Among the tested compounds, the compounds

C4, $\mathrm{C} 9$ and $\mathbf{C 1 0}$ have emerged as active against all tested microorganisms.

The antifungal and antibacterial activities of the C3, C9 could be attributed to the presence of halogen substituents. However, based on this promising observation, it is immature to arrive at the conclusion on structure activity aspect of these molecules and further evaluation is needed. The data is given in the Table. 2 and the minimum inhibitory concentration (MIC) values of the compounds tested against bacteria and fungi are given in the Table 3.

Table 3. Minimum Inhibitory Concentrations (MIC) activity of the new chalcones C1-C10 (MIC in $\mu \mathrm{g} / \mathrm{mL}$ )

\begin{tabular}{|c|c|c|c|c|c|c|}
\hline Compounds & $\begin{array}{c}\text { Staphylococcus } \\
\text { aureus }\end{array}$ & $\begin{array}{l}\text { Bacillus } \\
\text { subtilis }\end{array}$ & $\begin{array}{c}\text { Salmonella } \\
\text { typhi }\end{array}$ & $\begin{array}{c}\text { Escherichia } \\
\text { coli }\end{array}$ & $\begin{array}{c}\text { Aspergillus } \\
\text { niger }\end{array}$ & $\begin{array}{l}\text { Candida } \\
\text { albicans }\end{array}$ \\
\hline C1 & 30 & 30 & 40 & 30 & 30 & 30 \\
\hline $\mathrm{C} 2$ & 30 & 40 & 30 & 30 & 20 & 30 \\
\hline C3 & 30 & 30 & 30 & 20 & 30 & 40 \\
\hline C4 & 30 & 30 & 40 & 30 & 30 & 20 \\
\hline C5 & 30 & 40 & 30 & 30 & 40 & 40 \\
\hline C6 & 40 & 30 & 40 & 40 & 20 & 30 \\
\hline C7 & 30 & 30 & 40 & 40 & 20 & 20 \\
\hline C8 & 40 & 30 & 20 & 40 & 40 & 30 \\
\hline C9 & 30 & 20 & 30 & 20 & 30 & 30 \\
\hline C10 & 40 & 30 & 30 & 10 & 10 & 40 \\
\hline
\end{tabular}

\subsection{Colony forming units (CFU) studies}

Each colony forming unit represents a bacterium that was present in the sample. This study was basically carried out to see the survival of the bacteria under radiation. The count of CFU in compound treated and irradiated bacteria samples reveal the protective effect of compounds. In irradiated bacteria sample the CFU were reduced significantly. Where as in compound treated and irradiated samples significant increase in CFU was observed. This data is depicted in the Table 4. 
Table 4. Colony forming unit studies of E. coli K12 during post radiation treatments.

\begin{tabular}{lllllllll}
\hline Control & Irradiated & & \multicolumn{3}{c}{ C 5 + radiation } & \multicolumn{2}{c}{ C7 + radiation } & \multicolumn{2}{c}{ C8 } & + radiation \\
$(\mathrm{DMSO})$ & $0.2 \mathrm{~Gy}$ & $0.4 \mathrm{~Gy}$ & $0.2 \mathrm{~Gy}$ & $0.4 \mathrm{~Gy}$ & $0.2 \mathrm{~Gy}$ & $0.4 \mathrm{~Gy}$ & $0.2 \mathrm{~Gy}$ & $0.4 \mathrm{~Gy}$ \\
$1.92 \times 10^{7}$ & $0.87 \times 10^{7}$ & $0.67 \times 10^{7}$ & $1.71 \times 10^{7}$ & $1.64 \times 10^{7}$ & $1.24 \times 10^{7}$ & $1.05 \times 10^{7}$ & $1.16 \times 10^{7}$ & $1.09 \times 10^{7}$ \\
\hline
\end{tabular}

\subsection{Putative molecular interactions with metRS by molecular docking simulations}

The chalcones C1-C10 have been docked into the active site of the methionyl-tRNA synthetase (metRS) (PDB ID: 1A8H). The calculated docking and binding $(\Delta \mathrm{G})$ energies (in $\mathrm{Kcal} / \mathrm{mol}$ ) of the compounds are shown in Table 5. Based on the calculated binding energies compounds C4, C9 and C10 should be potent antibacterials.

Table. 5. Calculated binding $(\Delta \mathrm{G})$ energies of the compounds against metRS

\begin{tabular}{ll}
\hline & Calculated binding \\
Compounds & \\
& Energies \\
& $(\Delta \mathrm{G}$ in $\mathrm{Kcal} / \mathrm{mol}$ \\
C1 & -3.5 \\
C2 & -1.7 \\
C3 & -4.7 \\
C4 & -0.8 \\
C5 & -1.1 \\
C6 & -1.3 \\
C7 & -1.0 \\
C8 & -0.7 \\
C9 & -4.1 \\
C10 & -5.2 \\
\hline
\end{tabular}




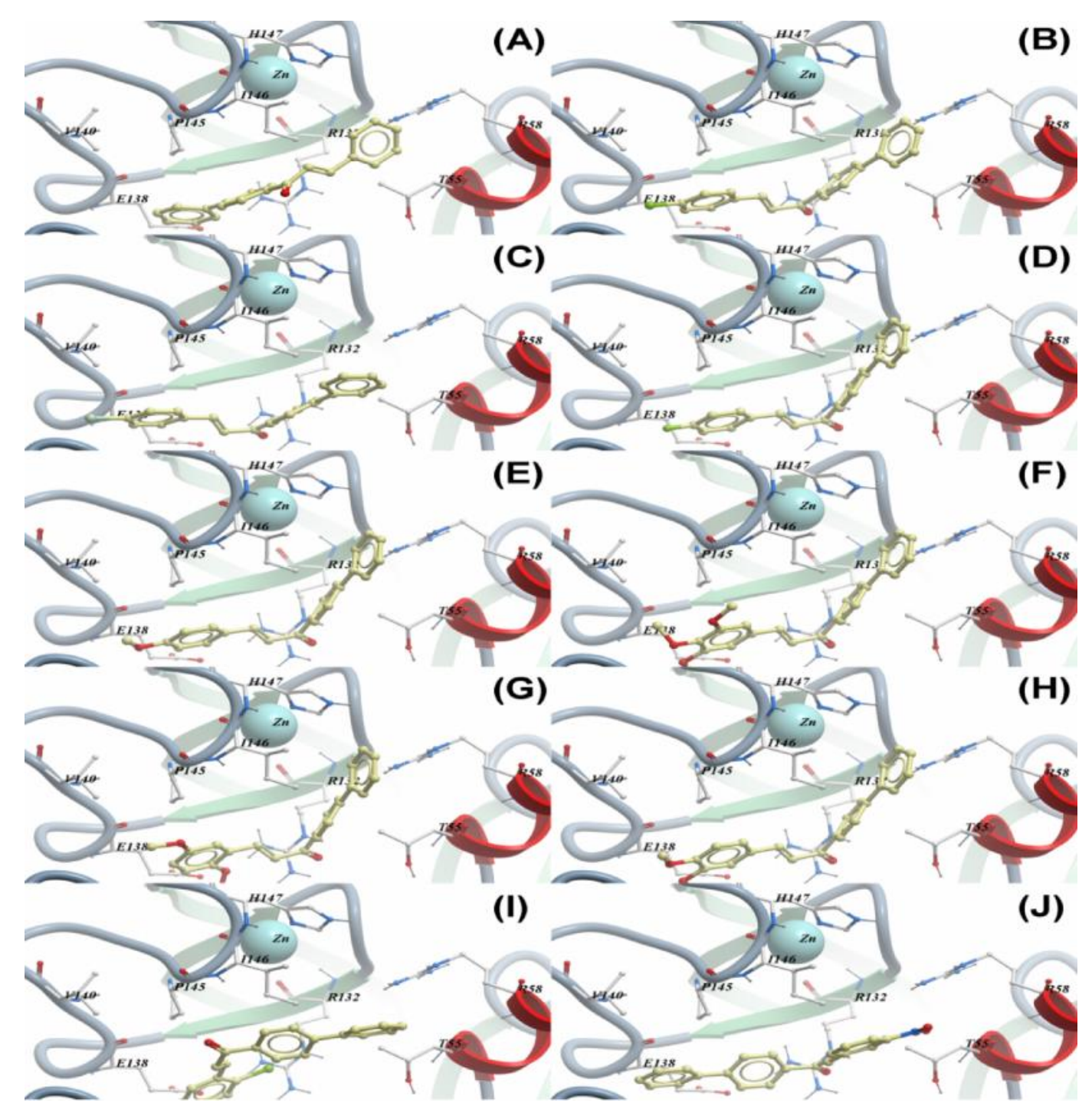

Fig.6. Molecular interactions with of the chalcones C1 (A), C2 (B), C3 (C), C4 (D), C5 (E), C6 (F), C7 (G), C8 (H), C9 (I) and C10 (J) against methionyl-tRNA synthetase (metRS) (PDB ID: 1A8H). Yellow stick models are the chalcones docked at the active site of metRS and only polar hydrogens are shown.

Carbon atoms from the ring systems of the compounds $\mathbf{C 1}, \mathbf{C 2}$ and $\mathrm{C} 3$ showed hydrophobic interactions with Glu138, Pro145, Ile146 and Thr55. Other than the hydrophobic interactions the ketonic oxygen of compounds $\mathbf{C 4}$ and $\mathbf{C 5}$ formed hydrogen bonds with the $\mathrm{NH}_{2}(2.36 \AA)$ and NE (2.43 $\AA$ ) atoms of $\operatorname{Arg} 132$. Compound C6 also have very similar hydrophobic interactions in addition to Val140 with the side of trimethoxyphenyl part of the compound and 
hydrogen bonds are also same, but little longer in distance, $\mathrm{NH}_{2}(2.42 \AA)$ and NE $(2.63 \AA)$ atoms of Arg132. In the cases of compounds $\mathbf{C 7}$ and $\mathbf{C 8}$ hydrogen bonds are $\mathrm{NH}_{2}(\sim 2.51 \AA)$ and NE ( 2.35 ̊) atoms of Arg132.Compound C9 exhibited similar hydrophobic interactions with Glu138, Pro145, Ile146 and Thr55. In the cases of compound C10 in addition to the hydrophobic interactions like other compounds (with Glu138, Pro145, Ile146 and Thr55) hydrogen bonds are $\mathrm{NH}_{2}(\sim 2.75 \AA)$ and $\mathrm{NE}(\sim 2.68 \AA)$ atoms of Arg132. The molecular interactions between the chalcones and the active site residues of metRS at 3D space are shown in Fig. 6 different compounds in different panels, accordingly.

\section{EXPERIMENTAL}

\subsection{Chemistry}

Melting points were determined in an open capillary tube and are uncorrected. IR spectra were recorded in $\mathrm{KBr}$ on a JASCO FT/IR-5300. The mass spectra were recorded on SHIMADZU - LCMS 2010 Spectrometer. Elemental analysis was carried out on a FLASH EA 1112 SERIES CHN REPORT THERMO FINNIGAN. All chemicals were purchased from Sigma-Aldrich Co., U.S.A., and the solvents used for column chromatography were of reagent grade, and were purchased from commercial sources. The compounds were purified and monitored by thin layer chromatography on pre-coated sheets of silica gel-G (Merck, Germany) using iodine vapour for detection.

\subsection{General Procedure for the synthesis chalcones (C)}

Chalcones were synthesized by Clasien- Schmidt condensation using MeOH/EtOH/DMF as reaction solvent. A mixture of 4- phenyl acetophenone $(0.01 \mathrm{~mol})$ and substituted benzaldehyde $(0.01 \mathrm{~mol})$ in ethanol $(25 \mathrm{~mL})$ was cooled for $10-15^{\circ} \mathrm{C}$ in ice bath. To cooled solution was added $50 \%(8 \mathrm{~mL}) \mathrm{NaOH}$ drop by drop with continuous stirring for 5 hours using magnetic stirrer and left for overnight. The reaction mixture was poured onto crushed ice and acidified using dilute $\mathrm{HCl}$. The solid obtained was filtered, washed with ice cold water, dried and recrystallized from ethanol and \% yield and meting point were noted [12]

C1: (2E)-1-(Biphenyl-4-yl)-3-phenyl)prop-2-en-1-one

${ }^{1} \mathrm{H}$ NMR (300 MHz, d $\mathrm{d}_{6}$-DMSO): $\delta 7.90$ (s, 1H), 7.87 (m, 2H), 7.67 (m, 2H), $7.56(\mathrm{~s}, \quad 1 \mathrm{H})$, 
$7.48(\mathrm{~m}, 2 \mathrm{H}), 7.32(\mathrm{~m}, 2 \mathrm{H}), 7.30(\mathrm{~m}, 2 \mathrm{H}), 7.22(\mathrm{~m}, 1 \mathrm{H}), 7.21(\mathrm{~m}, 2 \mathrm{H}), 7.14(\mathrm{~m}, 1 \mathrm{H})$.

C2 :(2E)-1-(Biphenyl-4-yl)-3-(4-chlorophenyl)prop-2-en-1-one

${ }^{1} \mathrm{H}$ NMR (300 MHz, d6-DMSO): $\delta 7.90$ (s, 1H), 7.87 (m, 2H), 7.67 (m, 2H), 7.56 (s, 1H) , $7.48(\mathrm{~m}, 2 \mathrm{H}), 7.32(\mathrm{~m}, 2 \mathrm{H}), 7.30(\mathrm{~m}, 2 \mathrm{H}), 7.22(\mathrm{~m}, 1 \mathrm{H}), 7.21(\mathrm{~m}, 2 \mathrm{H})$.

C3 :(2E)-1-(Biphenyl-4-yl)-3-(4-bromophenyl)prop-2-en-1-one

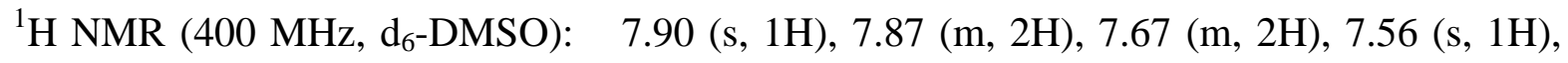
$7.48(\mathrm{~m}, 2 \mathrm{H}), 7.38(\mathrm{~m}, 2 \mathrm{H}), 7.32(\mathrm{~m}, 2 \mathrm{H}), 7.22(\mathrm{~m}, 1 \mathrm{H}), 7.19(\mathrm{~m}, 2 \mathrm{H})$.

C4: (2E)-1-(Biphenyl-4-yl)-3-(4-fluorophenyl)prop-2-en-1-one

${ }^{1} \mathrm{H}$ NMR (400 MHz, d6-DMSO): $\delta 7.90$ (s, 1H), 7.87 (m, 2H), 7.67 (m, 2H), 7.56 (s, 1H), $7.48(\mathrm{~m}, 2 \mathrm{H}), 7.38(\mathrm{~m}, 2 \mathrm{H}), 7.32(\mathrm{~m}, 2 \mathrm{H}), 7.28(\mathrm{~m}, 1 \mathrm{H}), 7.22(\mathrm{~m}, 2 \mathrm{H}), 6.92(\mathrm{~m}, 2 \mathrm{H})$.

C5:(2E)-1-(Biphenyl-4-yl)-3-(4-methoxyphenyl)prop-2-en-1-one

${ }^{1} \mathrm{H}$ NMR (400 MHz, d6-DMSO): $\delta 7.90$ (s, 1H), 7.87 (m, 2H), 7.67 (m, 2H), 7.56 (s, 1H), $7.48(\mathrm{~m}, 2 \mathrm{H}), 7.32(\mathrm{~m}, 2 \mathrm{H}), 7.22(\mathrm{~m}, 1 \mathrm{H}), 7.19(\mathrm{~m}, 2 \mathrm{H}), 6.72(\mathrm{~m}, 2 \mathrm{H}), 3.73(\mathrm{~s}, 3 \mathrm{H})$. LCMS (m/z, \%), 315(M+1, 190), $316(\mathrm{M}+2,45), 197\left(\mathrm{C}_{14} \mathrm{H}_{13} \mathrm{O}, 100\right)$

C6: (2E)-1-(Biphenyl-4-yl)-3-(3,4,5-trimethoxyphenyl)prop-2-en-1-one

${ }^{1} \mathrm{H}$ NMR (400 MHz, d6-DMSO): $\delta 7.90$ (s, 1H), 7.87 (m, 2H), 7.67 (m, 2H), 7.56 (s, 1H) , $7.48(\mathrm{~m}, 2 \mathrm{H}), 7.32(\mathrm{~m}, 2 \mathrm{H}), 7.22(\mathrm{~m}, 1 \mathrm{H}), 6.26(\mathrm{~s}, 2 \mathrm{H}), 3.73(\mathrm{~s}, 9 \mathrm{H})$. LCMS (m/z, \%), 375.5 (M+1, 100), 376.5(M+2, 40), $348.4(20), 197\left(\mathrm{C}_{14} \mathrm{H}_{13} \mathrm{O}, 100\right)$

C7: (2E)-1-(Biphenyl-4-yl)-3-(2,5-dimethoxyphenyl)prop-2-en-1-one

${ }^{1} \mathrm{H}$ NMR (400 MHz, d6-DMSO): $\delta 8.17$ (s, 1H), 7.87 (m, 2H), 7.67 (m, 2H), 7.48 (m, 2H), $7.39(\mathrm{~s}, 1 \mathrm{H}), 7.32(\mathrm{~m}, 2 \mathrm{H}), 7.22(\mathrm{~m}, 1 \mathrm{H}), 6.70(\mathrm{~s}, 1 \mathrm{H}), 6.61(\mathrm{~s}, 1 \mathrm{H}), 6.54(\mathrm{~d}, 1 \mathrm{H}), 3.73(\mathrm{~s}, 6 \mathrm{H})$. LCMS (m/z, \%), $345(\mathrm{M}+1,50), 346(\mathrm{M}+2,30), 197\left(\mathrm{C}_{14} \mathrm{H}_{13} \mathrm{O}, 100\right)$

C8: (2E)-1-(Biphenyl-4-yl)-3-(3,4-dimethoxyphenyl)prop-2-en-1-one ${ }^{1} \mathrm{H}$ NMR (400 MHz, d6-DMSO): $\delta 7.90$ (s, 1H), 7.87 (m, 2H), 7.67 (m, 2H), 7.56(s, 1H) , $7.48(\mathrm{~m}, 2 \mathrm{H}), \quad 7.32(\mathrm{~m}, 2 \mathrm{H}), 7.22(\mathrm{~m}, 1 \mathrm{H}), 6.75-6.70(\mathrm{~m}, 2 \mathrm{H}), 6.61(\mathrm{~m}, 1 \mathrm{H}), 3.73(\mathrm{~s}, 6 \mathrm{H})$. LCMS (m/z, \%), $345(\mathrm{M}+1,50), 346(\mathrm{M}+2,30), 197\left(\mathrm{C}_{14} \mathrm{H}_{13} \mathrm{O}, 100\right)$ C9:(2E)-1-(Biphenyl-4-yl)-3-(2-chlorophenyl)prop-2-en-1-one

${ }^{1} \mathrm{H}$ NMR (400 MHz, d6-DMSO): $\delta 8.27$ (m, 3H), 8.26 (d, 2H), 7.88 (d, 2H), 7.78 (d, 2H), 7.48 (m, 6H). LCMS (m/z, \%), 319 (M+1,35), $293(\mathrm{M}+2,15) 197\left(\mathrm{C}_{14} \mathrm{H}_{13} \mathrm{O}, 100\right)$. 
C10:(2E)-1-(Biphenyl-4-yl)-3-(3-bromo-4-methoxyphenyl)prop-2-en-1-one

${ }^{1} \mathrm{H}$ NMR (300 MHz, d6-DMSO): $\delta 7.92$ (m, 3H), 7.69 (m, 1H), 7.59(m, 2H), 7.48 (m, 2H), 7.32(m, 2H), $7.22(\mathrm{~m}, 1 \mathrm{H}), 6.77(\mathrm{~d}, 1 \mathrm{H}), 3.81(\mathrm{~s}, 2 \mathrm{H}), 3.73(\mathrm{~s}, 3 \mathrm{H})$. LCMS (m/z, \%), 393 (M, 80), $197\left(\mathrm{C}_{14} \mathrm{H}_{13} \mathrm{O}, 100\right)$.

\subsection{Determination of antioxidant activity by DPPH scavenging assay}

The DPPH assay was carried out according to standard method with slight modifications. The absorbance of stable DPPH• was read at $517 \mathrm{~nm}$ using UV-vis. spectrophotometer and the remaining DPPH was calculated. [13].

\subsection{Modulatory effect of compounds against oxidative stress induced by gamma radiation}

\subsubsection{Bacterial Strain, Culture Conditions and preparation of bacteria for irradiation}

Stocks of E. coli K12 were routinely maintained on slopes of nutrient agar and sub cultured into LB broth, which was incubated overnight at $37^{\circ} \mathrm{C}$ under the moderate aeration. An overnight broth culture was inoculated into $5 \mathrm{ml}$. broth, which was incubated for $1.5 \mathrm{hr}$. From this culture $0.2 \mathrm{~mL}$ was inoculated into a fresh bottle containing $5 \mathrm{~mL} \mathrm{LB}$ broth, which was rotated in the incubator for $1.7 \mathrm{hr}$. The suspensions were centrifuged and washed three times with phosphate buffer ( $\mathrm{pH}$ 6.9) and finally resuspended in buffer. This was used for further studies with suitable dilutions. E. coli K12 taken from the stock was grown aerobically in liquid $\mathrm{LB}$ broth at $37^{\circ} \mathrm{C}$ at $150 \mathrm{r} / \mathrm{min}$. The compounds $\mathbf{C 5}, \mathbf{C 7}$ and $\mathbf{C 8}$ at the concentration of $20 \mu \mathrm{g} / \mathrm{ml}$ was added to cultures at the same time of inoculation which were then incubated for $24 \mathrm{~h}$ before harvesting for enzyme activity studies. DMSO solvent was used to dissolve C5,

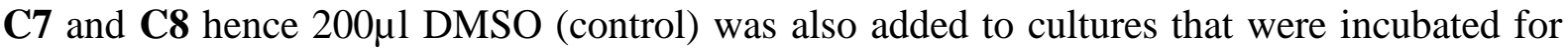
$24 \mathrm{~h}$ in liquid LB medium [14].

\subsubsection{Irradiation of bacteria sample}

Irradiations of bacteria samples in polypropylene vials were done under telecobalt radiotherapy unit [Phoenix (\#P44)] at Kasturba Medical College Hospital, Attavar, Mangalore. This unit is of medical use for the treatment of malignant diseases which is having a Cobalt60 radioactive source [produces gamma radiation energy of $1.17 \mathrm{MeV} \& 1.33 \mathrm{MeV}$; with an activity of 170 RMM (Roentgen per minute at one meter)]. 
Polypropylene vials (containing bacteria culture in LB media) were kept under water phantom at a specified depth as shown in Fig.(2a). The vials were irradiated to doses of 0.2Gray and 0.4 Gray under cobalt unit which is illustrated Fig.(2b).

\subsubsection{Bacteria Harvest and Lysis Procedures}

Bacteria cells were harvested from $6 \mathrm{~mL}$ liquid culture by centrifugation and washed twice using ice-cold $0.9 \%$ sodium chloride solution. Pellets were re-suspended in $3 \mathrm{~mL} 0.9 \%$ sodium chloride solution and then subjected to 99 cycling of sonication in an ice water bath for $3 \mathrm{~s}$ followed by cooling for another $4 \mathrm{~s}$. Cellular debris was removed by centrifugation at $10000 \mathrm{~g}$ at $4^{\circ} \mathrm{C}$. The supernatants were collected for SOD, CAT, and TBARS levels were determined.

\subsubsection{Enzymatic activity measurements}

Bacteria homogenate were used for Catalase activity measurements. Dismutation of hydrogen peroxide by catalase was registered using spectrophotometer at $240 \mathrm{~nm}$ [15]. The activity of SOD was assayed at $406 \mathrm{~nm}$ as the inhibition of quercetin oxidation by superoxide anion [16,17].Protein estimation was carried out using bacteria homogenate by Lowery's method [18].

\subsubsection{Thiobarbituric acid-reactive substances}

TBARS were measured in bacteria cell suspension by the standard procedure [19]. For this, $1.0 \mathrm{ml}$ cell suspension (about 2-3 $\mu \mathrm{g}$ of protein) was precipitated by the addition of $1.0 \mathrm{ml}$ of $20 \% \mathrm{w}: \mathrm{v}$ TCA, centrifuged and the supernatants were mixed with $2.0 \mathrm{ml}$ of saturated solution of thiobarbituric acid in $0.1 \mathrm{M} \mathrm{HCl}$ and $10 \mathrm{mM}$ butylated hydroxytoluene. The samples were heated for $60 \mathrm{~min}$ at $100^{\circ} \mathrm{C}$ in a water bath. $1.5 \mathrm{ml}$ aliquot was then removed, chilled and mixed with $1.5 \mathrm{ml}$ of butanol. The mixture was centrifuged for $10 \mathrm{~min}$ at $4000 \mathrm{~g}$. The organic fraction was removed and optical density at $535 \mathrm{~nm}$ was measured using spectrophotometer

\subsubsection{Colony forming unit study during post irradiation treatment}

Microbial counting is useful in the basic sciences and is used determine the number of bacteria present for physiological or biochemical studies. After irradiation, the cultures were immediately stored at $4{ }^{\circ} \mathrm{C}$, and the changes of the microbial growth, were analyzed during the post-irradiation period. Media for an enumeration of the bacteria were prepared by 
Standard Plate Count Agar. The non irradiated and irradiated samples were serially diluted with sterile saline and each diluent $(100 \mathrm{~mL})$ was spread in triplicate on to each agar plate. The agar plates were incubated at $37^{\circ} \mathrm{C}$ for $48 \mathrm{~h}$ and then the colony forming units (CFU) per milliliter of the sample were calculated [19].

\subsection{Antibacterial screening and Minimum inhibitory concentration}

\subsubsection{Antibacterial activity}

The newly synthesized chalcone derivatives C1-C10 were screened for their antibacterial activity against bacterial strains by disc diffusion method. Fluconazole was used as a standard drug. Solvent and growth controls were kept [20].

\subsubsection{Minimum Inhibitory Concentrations (MIC)}

The MIC of all synthesized compounds C1-C10 was determined by a micro dilution method. The respective clinical strain was spread separately on the medium. The wells were created using a stainless steel sterilized cork borer under aseptic conditions. The compounds C1-C10 at different concentrations viz. 10, 20, 30, 40 and 50 $\mu \mathrm{g}$ was dissolved DMSO and later loaded into corresponding wells. The standard drug Ciprofloxacin $(40 \mu \mathrm{g}$ in100 L) and F Fluconazole (40 $\mu \mathrm{g}$ in100 1) were used as standard drugs for comparison of antibacterial and antifungal activities respectively. The zone of inhibition was compared with standard drug after $24 \mathrm{~h}$ of incubation at $37^{\circ} \mathrm{C}$ for antibacterial activity and $72 \mathrm{~h}$ at $25^{\circ} \mathrm{C}$ for antifungal activity [20].

\subsection{Docking calculations with $\mathrm{ICM}^{\mathrm{TM}}$ (Internal Coordinate Mechanics) dock.}

All the docking calculations of compounds C1-C10 in this article were performed using the $\mathrm{ICM}^{\mathrm{TM}}$ docking module with the default setup as earlier mentioned [21]

\subsubsection{Preparations of the inhibitors and target molecules}

The 2D structures of the chalcones (in mol file formats) have been converted to 3D and energy minimized at the 3D space of ICM environment. The atom types using local chemical environment, Merck Molecular Force Field (MMFF) 3-9 formal charges and 3D topology were assigned. The lowest energy conformers of chalcones were then docked into targets for antibacterials, the target was methionyl-tRNA synthetase (metRS) (PDB ID: 1A8H10).

\subsubsection{Docking process}


All the docking calculations were performed using the 'interactive docking' menu at the ICM environment. After docking the stack of docking poses were checked visually. Multiple stack conformations were selected based on their docking energies, rmsd values (compared between the docked model and x-ray conformation) and similarities to closely related x-ray crystal structures from PDB. Then the best conformations for each of the compounds were finally chosen, and then their binding energies were calculated using ICM script (briefly described in the following 'Calculation' section). The correlation between the activity profiles and the binding energies (Cal. $\Delta \mathrm{G})$ are presented in Result and discussion section.

\subsubsection{Calculations of free energies of binding}

For each of the individual docked complexes the free energies of binding (Cal. $\Delta \mathrm{G})$ between the protein and ligand was calculated using ICM script utilizing the equations 2 and 3.11

$\Delta \mathrm{G}=\Delta \mathrm{GH}+\Delta \mathrm{GEL}+\Delta \mathrm{GS}+\mathrm{C}$

$\Delta \mathrm{G}=\Delta \mathrm{GH}+\Delta \mathrm{GCOUL}+\Delta \mathrm{GDESOLV}+\Delta \mathrm{GS}+\mathrm{C}$

Here $\Delta \mathrm{GH}$ is the hydrophobic or cavity term, which accounts for the variation of water/non-water interface area. $\triangle \mathrm{GEL}$ is the electrostatic term composed of coulombic ( $\triangle$ GCOUL) interactions and desolvation $(\triangle \mathrm{GDESOLV})$ of partial charges transferred from an aqueous medium to a protein core environment. $\Delta \mathrm{GS}$ is the entropic term which results from the decrease in the conformational freedom of functional groups buried upon complexation; and finally the $\mathrm{C}$ is a constant accounts for the change of entropy of the system due to the decrease of free molecules concentration (cratic factor), and loss of rotational/translational degrees of freedom [22]

\subsubsection{Interpretations of intermolecular interactions}

To study the intermolecular interactions between the targets and the compounds LigPlot12 were used to plot the interactions from 3D to 2D. Beside LigPlot, ICM (www.molsoft.com) and Discovery Studio Visualizer (www.accelrys.com) also been used to analyze the interactions in $3 \mathrm{D}$ space.

\section{CONCLUSION}


A new series of chalcone derivatives C1-C10 were synthesized by the reaction of 4- phenyl acetophenone and substituted benzaldehydes in a Claisen Schmidt condensation reaction. They were characterized by analytical and spectral studies. The compounds were screened for DPPH scavenging activity. Among the tested compounds C5, C7 and C8 exhibited very good activity. Based on DPPH scavenging activity these molecules were selected to study modulatory effect on gamma radiation induced oxidative stress markers in E. coli K12. The compound (2E)-1-(biphenyl-4-yl)-3-(4-methoxyphenyl)prop-2-en-1-one C5 exhibited significant demolition effect in the levels of lipid peroxidation product [TBARS]. The compounds (2E)-1-(biphenyl-4-yl)-3-(2,5-dimethoxyphenyl)prop-2-en-1-one $\quad \mathbf{C 7}$ and (2E)-1-(biphenyl-4-yl)-3-(3,4-dimethoxyphenyl)prop-2-en-1-one C8 showed good activity towards demolition effect of TBARS level compared to irradiated sample but no statistically significant result was found compared to control. All the tested compounds were effective in bringing antioxidant enzyme levels [SOD and CAT] to near basal level in comparison with non irradiated and irradiated controls. The count of Colony Forming Units (CFU) of E coli in the compound treated irradiated samples also supported the radioprotective effect of the chalcone derivatives. In antifungal and antibacterial property evaluation studies the compounds exhibited promising activities. Among them compounds, (2E)-1-(biphenyl-4-yl)-3-(4-fluorophenyl) prop-2-en-1-one $\quad \mathbf{C 4}$ and (2E)-1-(biphenyl-4-yl)-3-(2-chlorophenyl) prop-2-en-1-one C9 exhibited good activity. The in silico inhibitor efficiency of newly synthesized compounds was evaluated with methionyl-tRNA synthetase for antibacterial activity. Among the tested compounds the compounds C3, C9 and C10 showed -4.7, -4.1 and -5.2 binding energies respectively. This results support the in vitro antimicrobial activity studies. Hence this further opens scope for screening of these newly synthesized molecules for probable antioxidant, radioprotective and antimicrobial activities in higher model system.

\section{ACKNOWLEDGEMENTS}

One of the authors B. K. Sarojini gratefully acknowledges the Department of Atomic Energy (DAE)/BRNS, Government of India, for providing financial assistance in the BRNS Project 
(No. 2008/34/05-BRNS/457). M. T. H. Khan is grateful to Prof. Ingebrigt Sylte, Medical Pharmacology and Toxicology, Department of Medical Biology, Faculty of Health Science, University of Troms $\varnothing$, N-9037 Troms $\varnothing$, Norway, for the access of the license of ICM-Pro version.

\section{REFERENCES}

[1] Shuryak I, Brenner D. J.A model of interactions between radiation-induced oxidative stress, protein and DNA damage in Deinococcus radiodurans, J. Theo. Bio., 2009 , $261305-317$.

[2] Rajesh A, Damodar G, Raman C, et al., Radioprotection by Plant Products: Present Status and Future Prospects, Phytother, Res., 2005,19, 1-22.

[3] Kim S.Y, Lee J. 3-D-QSAR study and molecular docking of methionyl-tRNA synthetase inhibitors. Bioorg Med Chem., 2003,11, 5325-5331.

[4] Hurdle J.G, O'Neill A.J. Chopra I. Prospects for aminoacyl-tRNA synthetase inhibitors as new antimicrobial agents. Antimicrob. Agents Chemother. 2005, 49 ,4821-4833

[5] Calliste C. A, Le Bail J.C, Trouilas P. et al., Chalcones; structural requirements for antioxidant, estrigenic and antiproliferative activities, Anticancer Res. 2001, 21, 3949-3956.

[6] Dominguez J. N, Leon C.J, Rodrigues N. G., et al., Synthesis and evaluation of new antimalarial phenylurenyl chalcone derivatives. J. Med. Chem. 2005, 48, 3654-3658.

[7] Narender T, Khaliq T. Shweta et al., Synthesis of Chromenchalcones and Evaluation of their in vitro Antileishmanial Activity. Bioorg. Med.Chem. 2005, 13, 6543-6550.

[8] N Cotelle, J.L. Bernier, J.P.Catteau, et al., Antioxidant properties of hydroxyflavones. Free Radic. Biol. Med. 1996, 20, 35-43.

[9] S Aleksandra, M Dragan, S Dejan, et al., Electrochemical behavior and antioxidant and prooxidant activity of natural phenolics.Molecules. 2007, 12, 2327-2340. 
[10] A.K.Ruby John, Sukumaran, K Girija, et al, Anticancer and antioxidant activity of synthetic chalcones and related compounds. Canc. Lettr. 1995, 97, 33-37.

[11] B.A.Arthington, M Motley, D.W.Warnock, et al., Quantitation of Candida albicans Ergosterol Content Improves the Correlation between In Vitro Antifungal Susceptibility Test Results and In Vivo Outcome after Fluconazole Treatment in a Murine Model of Invasive Candidiasis. Microbiol. 2000, 38, 2254-2260.

[12] Nakamura C. N, Kawasaki Miyataka H. et al., Synthesis and biological activities of fluorinated chalcone derivatives. Bioorg. \& Med. Chem. 2002, 10, 699-706.

[13] Sarojini B. K, Vidyagayatri M, Darshan Raj C. G.et al., DPPH Scavenging Assay of Novel 1,3-disubstituted-1H-pyrazol-5-ols and their in silico Studies on Some Proteins Involved in Alzheimer's Disease Signaling Cascade, Lett. in Drug Des. \& Discov. 2010, 7, 214-224.

[14] Collins A.H., (Ed.), Microbiological Methods, $2^{\text {nd }}$ ed.; Butterworth, London, 1976.

[15] Aebi H.Catalase in vitro, Meth. Enzymol. 1984, 105, 121-125.

[16] Kakkar B.D, Viswanathan P.N, A modified spectrophotometric assay of superoxide dismutase (SOD). Ind. J. Biochem. Biophys. 1984, 21,130-132.

[17] Darshan Raj C.G, Sarojini B. K., Bhanuprakash V. et al., Studies on radioprotective and antiviral activities of some bischalcone derivatives, Med. Chem.Res. 2012, (21), 2671-2679

[18] Lowry O.H., Rosebrough N.J., Farr A.L. et al., Protein measurement using Folin phenol reagent. J. Biol. Chem. 1951, 282, 943-946.

[19] Ohakawa H, Ohishi U, Yakgi K, Assay for lipid perox- ides in animal tissues by Thiobarbituric reaction. Anal.Biochem. 1979 (95)145-149

[20] Sarojini B. K, Krishna B. G,Darshanraj C. G. et al., Synthesis, characterization, in vitro and molecular docking studies of new 2,5-dichloro thienyl substituted thiazole derivatives for antimicrobial properties, Eur. J. Med. Chem. 2010, 4, 3490-3496

[21] Abagyan R. A, Totrov M, Kuznetsov D.A.A. New method for protein modelling and design: Applications to docking and structure prediction from the distorted native conformation J. Comp. Chem. 1994, 15, 488-506 
[22] Schapira M, Totrov M, Abagyan R et al., Prediction of the binding energy for small molecules, peptides and proteins, J. Mol. Recog, 1999, 12, 177-190

\section{How to cite this article:}

Darshan Raj C G, Sarojini B K, Sindhu Priya E S, Hassan Khan M T, Srinivas C, Manjula P S. Antistress and antimicrobial studies of biphenyl chalcone derivatives. J. Fundam. Appl. Sci., 2016, 8(3), 782-803. 